\title{
Simultaneous Determination of Ultraviolet Absorbers and Antibacterial Agents in Textiles by Ultra-High Performance Liquid Chromatography/Orbitrap High Resolution Mass Spectrometry
}

\author{
Chengyun Wang, Tangtang Xie*, Rong Xu, Junfeng Lin, Lixia Li \\ Shenzhen Entry-Exit Inspection and Quarantine Bureau, Shenzhen, China \\ Email: *tangtangxie@139.com
}

How to cite this paper: Wang, C.Y., Xie, T.T., Xu, R., Lin, J.F. and Li, L.X. (2017) Simultaneous Determination of Ultraviolet Absorbers and Antibacterial Agents in Textiles by Ultra-High Performance Liquid Chromatography/Orbitrap High Resolution Mass Spectrometry. World Journal of Engineering and Technology, 5, 1-18. https://doi.org/10.4236/wjet.2017.51B001

Received: November 14, 2016 Accepted: April 9, 2017 Published: April 12, 2017

\begin{abstract}
This paper reported a new analytical method for the simultaneous determination of seven benzotriazole ultraviolet absorbers and seven antibacterial agents in textiles. After ultrasonic extraction for the textile samples in methanol, the solutions were analyzed by ultra-high performance liquid chromotagraphy/orbitrap high resolution mass spectrometry (UPLC/Orbitrap HRMS). It showed that a good chromatographic separation for these target compounds was achieved by a Hypersil GOLD column $(100 \mathrm{~mm} \times 2.1 \mathrm{~mm} \times 1.9 \mu \mathrm{m})$ with a gradient elution of methanol and $0.1 \%$ aqueous formic acid solution (containing $0.5 \mathrm{mmol} / \mathrm{L}$ ammonium acetate). Triclosan and 4-chloro-3,5-dimethyl phenol (PCMX) were detected by the orbitrap HRMS in an electrospray ionization (ESI) negative mode while the other twelve target compounds were detected by orbitrap HRMS in ESI positive mode. Full scan experiment was performed over the range from $\mathrm{m} / \mathrm{z} 100$ to $\mathrm{m} / \mathrm{z} 500$. These target compounds were routinely detected with mass accuracy below $2 \times 10^{-6}(2 \mathrm{ppm})$ at the optimized conditions. The results showed that the limits of detection (LODs) were in the range from 0.1 to $0.3 \mu \mathrm{g} / \mathrm{kg}$. The blank samples were spiked at three levels and their average recoveries varied from $80.5 \%$ to $96.3 \%$ while the relative standard deviation (RSD) changed from $3.2 \%$ to $9.9 \%$. The present method was also applied for the determination of those ultraviolet absorbers and antibacterial agents in the commercial textiles.
\end{abstract}

\section{Keywords}

Ultra-High Performance Liquid Chromatography/Orbitrap High Resolution Mass Spectrometry, Benzotriazoleultraviolet Absorbers, Isothiazolinone, 
Triclosan, 4-Chloro-3,5-Dimethyl Phenol

\section{Introduction}

Functional finishing such as ultraviolet-resistance and antibiosisis often applied to textiles in order to improve their performance in use [1]-[8]. Benzotriazoles have an excellent absorption capacity to the ultraviolet light due to a phenolic group attached to benzotriazole structure, thus they are widely used as absorbers for enhancing the ultraviolet-resistance property of textiles [9]. Isothiazolinones, triclosan and 4-chloro-3,5-dimethyl phenol (PCMX) are the chemicals that have a broad spectrum of activity against fungi and bacteria, they are widely used as the antibacterial agents for the control of microorganisms in textile [10] [11]. However, benzotriazoles are basically the persistent, bio-accumulative and toxic compounds [9] [12]-[16] while isothiazolinones, triclosan and PCMX are the skin irritants and strong contact allergens [17]-[25]. Therefore, these chemicals are strictly regulated by many countries and organizations.

The typical ultraviolet absorbers used in textiles, i.e., benzotriazoles, are 2-(2H-benzotriazol-2-yl)-4,6-di-tert-butylphenol (UV-320), 2-tert-butyl-6-(5chloro-2H-benzotrizol-2-yl)-4-methylphenol (UV-326), 2,4-di-tert-butyl-6-(5chloro-benzotriazol-2-yl)phenol(UV-327), 2-(2H-benzotriazol-2-yl)-4,6-di-tertpentylphenol (UV-328), and 2-(2H-benzotriazol-2-yl)-4-(tert-butyl)-6-(sec-butyl) phenol (UV-350), among which UV-320 and UV-327 have been banned by the Japanese government since 2007. In Derective 2002/72/EC, the specific migration limit for UV-326 and UV-327 is $30 \mathrm{mg} / \mathrm{kg}$ [26]. UV-320, UV-327, UV-328 and UV-350 have been listed into the list of substances of very high concern (SVHC) by European Chemicals Agency (ECHA). At the same time, UV-320, UV-327, UV-328 and UV-350 have been restricted to use in ecological textiles by Oeko-Tex Standard 100 since 2016 [27]. The typical antibacterial agents used in textiles are PCMX, triclosan and isothiazolinones which include 4,5-dichloron-octyl-4-isothiazolin-3-one (DCOI), 2-methyl-4-isothiazolin-3-one (MI), 5chloro-2-methyl-4-isothiazolin-3-one (CMI), 2-n-octyl-4-isothiazolin-3-one (OI) and 1,2-benzoisothiazolin-3-one (BIT). Among them, DCOI is strictly restricted by European Regulation EN 528/2012 [23]. The use of MI, CMI and BIT in textiles for toys has been regulated by EN 71-9 [24], in which the contents of MI and CMI must be below $10 \mathrm{mg} / \mathrm{kg}$ while the total content of MI and CMI are controled within $15 \mathrm{mg} / \mathrm{kg}$. ECHA has prohibited the use of triclosan since 2015, while PCMX was included in the list of priority pollutants by Environmental Protection Agency (EPA). Therefore, the analytical methods that can efficiently quantify these substances in textiles is very important in order to monitor the contents of these substances in textiles from commercial market.

There were many methods reported in the literatures for the analysis of benzotriazoles, isothiazolinones, triclosan, and PCMX. Gas chromatography (GC), gas chromatography/mass spectroscopy (GC/MS), gas chromatography-tandem 
mass spectrometry (GC/MS-MS), high performance liquid chromatography (HPLC) or high performance liquid chromatography-tandem mass spectrometry (HPLC/MS-MS) was used to determine benzotriazoles and triclosan in textiles [28]-[40]. HPLC or HPLC/MS-MS method was also used to the analysis of isothiazolinone in textiles [41], waters [42], paper for food packaging [43] and toys [44] or PCMX in disinfectant and health nursing products [45]. Because of their low volatility, triclosan compounds must be pretreated to convert them to the more volatile species before GC or GC/MS or GC/MS-MS measurement [36] [37] [38]. Such a procedure is complicated and time-consuming. Compared to GC based methods, HPLC does not require a derivative pretreatment procedure. However, the quantitative analysis can be carried out only when the components have been separated completely from each other in the conventional HPLC/MS or HPLC/MS-MS method. Recently, an untargeted approach, based on high resolution mass spectrometry(HRMS) using orbitrap analyser, has been used in the determination of organic contaminants [46]. In this approach, all ions obtained are monitored without any pre-selection and the identification is achieved according to the exact mass of the analyte(s). A similar method based on anultrahigh performance liquid chromatography/orbitrap high resolution mass spectrometry (UPLC/Orbitrap HRMS) has been used for determining benzotriazoles in textiles [47]. We believe that it is possible to determine simultaneously fourteen target compounds (mentioned above) commonly presence in textiles by an improved method based on UPLC/Orbitrap HRMS.

The objective of this study was to develop a method for the simultaneous determination of seven benzotriazoles and seven antibiosis in textiles based on ultrasonic extraction and UPLC/Orbitrap HRMS. The main focus was to explore the capabilities of the orbitrap in the full-scan acquisition mode with high resolution for the quantification of these compounds. The sensitivity, accuracy and related performance characteristics of the present method were also evaluated.

\section{Materials and Methods}

\subsection{Reagents and Samples}

2-(2'-hydroxy-5'-methylphenyl) benzotriazole (UV-P, CAS No. 2240-22-4, purity 98.0\%), UV-326 (CAS No. 3896-11-5, purity 98.0\%) and UV-350 (CAS No. 36437-37-3, purity 98.0\%) were purchased from AccuStandard Inc. (New Haven, Connectinut, USA). CMI (CAS No. 26172-55-4, purity 99.0\%), triclosan (CAS No. 3380-34-5, purity 99.5\%), PCMX (CAS No. 88-04-0, purity 99.0\%) and UV-320 (CAS No. 3846-71-7, purity 99.0\%) were purchased from Dr. Ehrensterfer GmbH (Augsburg, Germany). UV-327 (CAS No. 3864-99-1, purity 98.0\%) was purchased from ChemService Inc. (West Chester, PA, USA). UV-328 (CAS No. 25973-55-1, purity 98.0\%), 2-(2H-benzotriazol-2-yl)-4-(1,1,3,3-tetramethylbutyl)phenol (UV-329, CAS No. 3147-75-9, purity 98.0\%) and DCOI (CAS No. 64359-81-5, purity 99.8\%) were purchased from Kasei Co. Ltd. (Tokyo, Japan). MI (CAS No. 2682-20-4, purity 99.9\%), OI (CAS No. 26530-20-1, purity 99.9\%) and BIT (CAS No. 2634-33-5, purity 99.2\%) were purchased from Sigma-Aldrich 
(St. Louis, MO, USA). Formic acid (purity 98.0\%) ammonium acetate (purity 98.0\%) were purchased from CNW Technologies GmbH (Dusseldorf, Germany). Methanol (HPLC purity) was purchased from Merck (Darmstadt, Germany). All organic solvents were HPLC-grade.

Stock solutions of the individual compounds were prepared in methanol (1000 $\mu \mathrm{g} / \mathrm{ml})$. Stock mixed solution of fourteen target compounds was prepared in methanol and the concentration was 4.100, 4.120, 9.200, 4.000, 8.000, 10.400, 8.600, $10.600,4.896,7.800,4.844,4.858,4.814$ and $4.854 \mu \mathrm{g} / \mathrm{mL}$ for UV-P, UV-350, UV326, triclosan, PCMX, UV-320, UV-327, UV-328, DCOI, UV-329, MI, OI, BIT and CMI, respectively. Working solutions $(0.1-200 \mu \mathrm{g} / \mathrm{l})$ were prepared in methanol. Stock solutions were stored at a temperature of $-18^{\circ} \mathrm{C}$ and working solutions were stored at a temperature of $4^{\circ} \mathrm{C}$. The ultrapure water was obtained by purifying demineralized water in a Milli-Q system (Millipore, Milford, MA, USA).

Eightpositive samples were all available commercially. Sample 1 was white cotton cloth (containing UV-327). Sample 2, 3 and 4 were army green woven polyester, beige woven polyester and white woven cotton, respectively (containing triclosan). Sample 5 was printed silkworm silk (containing PCMX). Sample 6,7 and 8 were plain woven men's shirt, plain woven dyeing women cotton top and woven silk dress, respectively (containing OI).

\subsection{Sample Preparation}

Textile samples were cut into pieces of about $5 \mathrm{~mm} \times 5 \mathrm{~mm}$ by automatic system prototype. Approximately $1.0 \mathrm{~g}$ of textile samples were weighed into $250 \mathrm{ml}$ grinding mouth Erlenmeyer flask. $20 \mathrm{ml}$ methanol was added into this flask. This flask was caped and ultrasonically extracted at $40^{\circ} \mathrm{C}$ for $30 \mathrm{~min}$. The extraction solution was filtered into a heart-shaped bottle and evaporated to near dryness in a vacuum rotary evaporator. The heart-shaped bottle was then transferred to a nitrogen blowing instrument and blown slowly to dry with dry nitrogen. The residue was dissolved in $1 \mathrm{ml}$ methanol and the resulting solution was filtered with $0.22 \mu \mathrm{m}$ membrane and analyzed by UPLC/Orbitrap HRMS technique. Appropriate dilution was carried out before analysis if necessary.

\subsection{Preparation of Spiked Samples}

Approximately $1.0 \mathrm{~g}$ of three different kinds of blank textiles swatches, such as white cotton substrate, white polyester substrate and cotton/polyester blended fiber, which were cut into pieces of about $5 \mathrm{~mm} \times 5 \mathrm{~mm}$ by automatic system prototype, were weighed into $250 \mathrm{ml}$ grinding mouth Erlenmeyer flask. A certain amount of standard stock solutions of fourteen target compounds was added to submerge the blank textile samples. After an equilibration time of $24 \mathrm{~h}$, the solvent was eliminated using a gentle stream of dry nitrogen. Then these samples were used for the spiked recovery experiments.

\subsection{Chromatographic Separation}

Analysis were performed with a Dionex Ultimate 3000-Q Exactive ultra-high 
performance liquid chromatography/orbitrap high resolution mass spectrometry (UPLC/Orbitrap HRMS) system (Thermo Scientific, MA, USA), equipped with a Dionex ultimate 3000 RS pump (Thermo Scientific, MA, USA) and a Dionex ultimate 3000 RS autosampler (Thermo Scientific, MA, USA). HPLC separation was performed using a Hypersil GOLD column $(100 \mathrm{~mm} \times 2.1 \mathrm{~mm} \times 1.9 \mu \mathrm{m}$, Thermo Scientific, MA, USA). The separation was performed with mobile phase consisting of $5 \mathrm{mmol} / \mathrm{l}$ ammonium acetate $(0.1 \%$ formic acid) (A)-methanol (B). The gradient program of elution was as follows: $0.00 \mathrm{~min}, 60 \% \mathrm{~A} / 40 \% \mathrm{~B}, 1.90$ $\mathrm{min}, 10 \% \mathrm{~A} / 90 \% \mathrm{~B}, 1.90-6.00 \mathrm{~min}, 10 \% \mathrm{~A} / 90 \% \mathrm{~B}, 6.01-9.00 \mathrm{~min}, 60 \% \mathrm{~A} / 40 \% \mathrm{~B}$. The total flow rate was $0.3 \mathrm{ml} / \mathrm{min}$ and the injection volume was $1.0 \mu \mathrm{l}$. The temperature of column was $40^{\circ} \mathrm{C}$ whereas the temperature of sampler was $7^{\circ} \mathrm{C}$.

\subsection{Orbitrap HRMS Conditions}

The Dionex Ultimate 3000-Q Exactive ultra-high performance liquid chromatography/orbitrap high resolution mass spectrometry system (Thermo Scientific, MA, USA), equipped with an electrospray ionization (ESI) source in positive and negative mode, a Dionex ultimate 3000 RS pump (Thermo Scientific, MA, USA) and a Dionex ultimate 3000 RS autosampler (Thermo Scientific, MA, USA) was chosen for the qualitative and quantitative analysis of fourteen target compounds. The spray voltage, capillary temperature, and auxiliary heating gas temperature were set at $3500 \mathrm{~V}, 320^{\circ} \mathrm{C}$ and $350^{\circ} \mathrm{C}$, respectively. The rate of flow of sheath gas and auxiliary gas were set at 30 arbitrary units and 10 arbitrary units, respectively. Chromatograms were recorded under the full scan mode with the resolution of 70000, over a range of $\mathrm{m} / \mathrm{z} 100-\mathrm{m} / \mathrm{z} 500$. The width of ion extraction window of Xcalibur 2.2 software was $5 \times 10^{-6}(5 \mathrm{ppm})$. The whole analytical parameters of UPLC/Orbitrap HRMS for fourteen target compounds were shown in Table 1.

Table 1. Analytical parameters of UPLC/Orbitrap HRMS for fourteen target compounds.

\begin{tabular}{|c|c|c|c|c|c|}
\hline \multirow[b]{2}{*}{ No. } & \multirow[b]{2}{*}{ Compounds } & \multirow[b]{2}{*}{ Formula } & \multicolumn{3}{|c|}{ exact mass } \\
\hline & & & $\begin{array}{c}\text { Theoretical } \\
\text { value }\end{array}$ & $\begin{array}{l}\text { Detected } \\
\text { value }\end{array}$ & $\begin{array}{c}\text { Error of the } \\
\text { accuracy/ppm }\end{array}$ \\
\hline 1 & PCMX & $\mathrm{C}_{8} \mathrm{H}_{9} \mathrm{OCl}$ & 155.02692 & 155.02707 & +0.97 \\
\hline 2 & triclosan & $\mathrm{C}_{12} \mathrm{H}_{7} \mathrm{Cl}_{3} \mathrm{O}_{2}$ & 286.94389 & 286.94431 & +1.46 \\
\hline 3 & UV-P & $\mathrm{C}_{13} \mathrm{H}_{11} \mathrm{~N}_{3} \mathrm{O}$ & 226.09749 & 226.09726 & -1.02 \\
\hline 4 & UV -320 & $\mathrm{C}_{20} \mathrm{H}_{25} \mathrm{~N}_{3} \mathrm{O}$ & 324.20704 & 324.20693 & -0.34 \\
\hline 5 & UV-326 & $\mathrm{C}_{17} \mathrm{H}_{18} \mathrm{~N}_{3} \mathrm{OCl}$ & 316.12112 & 316.12105 & -0.22 \\
\hline 6 & UV-327 & $\mathrm{C}_{20} \mathrm{H}_{24} \mathrm{~N}_{3} \mathrm{OCl}$ & 358.16807 & 358.16781 & -0.73 \\
\hline 7 & UV-328 & $\mathrm{C}_{22} \mathrm{H}_{29} \mathrm{~N}_{3} \mathrm{O}$ & 352.23824 & 352.23812 & -0.34 \\
\hline 8 & UV-329 & $\mathrm{C}_{20} \mathrm{H}_{25} \mathrm{~N}_{3} \mathrm{O}$ & 324.20704 & 324.20691 & -0.40 \\
\hline 9 & UV-350 & $\mathrm{C}_{20} \mathrm{H}_{25} \mathrm{~N}_{3} \mathrm{O}$ & 324.20704 & 324.20681 & -0.71 \\
\hline 10 & MI & $\mathrm{C}_{4} \mathrm{H}_{5} \mathrm{NOS}$ & 116.01646 & 116.01641 & -0.40 \\
\hline 11 & CMI & $\mathrm{C}_{4} \mathrm{H}_{4} \mathrm{NOSCl}$ & 149.97749 & 149.97731 & -1.20 \\
\hline 12 & MIT & $\mathrm{C}_{7} \mathrm{H}_{5} \mathrm{NOS}$ & 152.01646 & 152.01627 & -1.25 \\
\hline 13 & OI & $\mathrm{C}_{11} \mathrm{H}_{19} \mathrm{NOS}$ & 214.12601 & 214.12580 & -0.98 \\
\hline 14 & DCOI & $\mathrm{C}_{11} \mathrm{H}_{17} \mathrm{NOSCl}_{2}$ & 282.04807 & 282.04787 & -0.71 \\
\hline
\end{tabular}




\section{Results and Discussion}

In this work, fourteen target compounds were studied, including seven kinds of benzotriazole ultraviolet absorbers, five kinds of isothiazolinone antibacterial agents, PCMX and triclosan. To obtain the best analytical conditions, the optimization of the extraction procedure, the chromatographic separation and mass spectrometry parameter was necessary, especially when the method developed includes a mixture of compounds with a wide range of physicochemical properties.

\subsection{Procedure for the Sample Preparation}

The subjects of this study could be divided into four categories: benzotriazole ultraviolet absorbers, isothiazolinone antibacterial agents, PCMX and triclosan and their physicochemical properties varied greatly. Various methods aiming to extract these target compounds from textiles, such as microwave-assisted extraction, ultrasonic extraction and accelerated solvent extraction, were reported previously, among which ultrasonic extraction was a common method for the extraction of target compounds from textile samples. Target compounds in eight positive samples were first ultrasonically extracted using methanol as the extraction solvent and the extraction conditions were optimized. As for triclosan, the results demonstrated that the optimal extraction conditions were ultrasonic extraction at $40^{\circ} \mathrm{C}$ for $30 \mathrm{~min}$, using $25 \mathrm{ml}$ methanol as the extractions solvent. As for PCMX, the results demonstrated that the optimal extraction conditions were ultrasonic extraction for $15 \mathrm{~min}$, using $20 \mathrm{ml}$ methanol as the extraction solvent. On the other hand, the extraction temperature had no evident influence on the extraction. For isothiazolinone antibacterial agents, the results demonstrated that the optimal extraction conditions were ultrasonically extracted at $45^{\circ} \mathrm{C}$ for $20 \mathrm{~min}$, using $20 \mathrm{ml}$ methanol as the extraction solvent. As for benzotriazole ultraviolet absorbers, the results showed that the optimal conditions were ultrasonically extracted at $45^{\circ} \mathrm{C}$ for $30 \mathrm{~min}$, using $20 \mathrm{ml}$ methanol as the extraction solvent. In order to comprehensively assess the impact of three factors such as extraction time (Factor A), extraction temperature (Factor B) and solvent volume (Factor $\mathrm{C}$ ) on the extraction amounts, orthogonal experiments were performed as shown in Table 2. The extraction amounts of eight positive samples were detected under condition No. 1 to condition No. 9. The optimal extraction conditions varied from each other for these eight positive samples. The orthogonal experimental data in Table 2 were analyzed to obtain the maximum gap and optimal conditions for each positive samples, as shown in Table 3. Obviously, extraction time (Factor $\mathrm{A}$ ) has the largest effect on the extraction amounts while extraction temperature (Factor B) has the smallest effect on the extraction amounts. Taking three factors into consideration, two programs such as $\mathrm{A} 1 \mathrm{~B} 2 \mathrm{C} 1$ and $\mathrm{A} 2 \mathrm{~B} 2 \mathrm{C} 1$ were chosen to be alternate optimal conditions and marked as No. 10 and No. 11, respectively, in Table 2. The extraction amounts of eight positive samples were all larger in condition No. 10 than in condition No. 11. At the same time, the extraction amounts of eight positive samples were larger than or 
Table 2. Orthogonal experiments ( $\mathrm{mg} / \mathrm{kg})$.

\begin{tabular}{ccccccccccccc}
\hline No. & Factor A & Factor B & Factor C & Sample 1 & Sample 2 & Sample 3 & Sample 4 & Sample 5 & Sample 6 & Sample 7 & Sample 8 \\
\cline { 2 - 10 } & Time/min & Temperature $/{ }^{\circ}$ C & Volume/ml & UV-327 & triclosan & triclosan & triclosan & PCMX & OI & OI & OI \\
\hline $\mathbf{1}$ & 30 & 45 & 20 & 106.9 & 6948.5 & 3781.4 & 7675.8 & 66.6 & 7936.8 & 8968.4 & 6018.7 \\
$\mathbf{2}$ & 30 & 40 & 15 & 94.7 & 6906.7 & 3752.8 & 7613.5 & 65.8 & 7889.4 & 8920.3 & 5912.6 \\
$\mathbf{3}$ & 30 & 50 & 25 & 101.3 & 6983.7 & 3812.5 & 7696.7 & 66.2 & 7853.5 & 8885.2 & 5832.4 \\
$\mathbf{4}$ & 25 & 45 & 15 & 99.4 & 6713.6 & 3665.5 & 7456.4 & 65.2 & 7986.3 & 9032.4 & 5978.5 \\
$\mathbf{5}$ & 25 & 40 & 25 & 88.5 & 6847.3 & 3715.8 & 7588.6 & 65.6 & 8027.5 & 9065.7 & 6017.8 \\
$\mathbf{6}$ & 25 & 50 & 20 & 94.9 & 6765.8 & 3674.2 & 7463.2 & 66.1 & 8063.2 & 9118.3 & 6032.6 \\
$\mathbf{7}$ & 35 & 45 & 25 & 91.8 & 6901.2 & 3742.5 & 7603.8 & 65.1 & 7789.6 & 8801.4 & 5832.7 \\
$\mathbf{8}$ & 35 & 40 & 20 & 89.7 & 6876.4 & 3741.2 & 7544.9 & 65.8 & 7845.8 & 8867.1 & 5996.5 \\
$\mathbf{9}$ & 35 & 50 & 15 & 96.8 & 6859.8 & 3721.3 & 7583.5 & 64.6 & 7736.8 & 8742.8 & 5865.9 \\
$\mathbf{1 0}$ & 30 & 40 & 20 & 105.3 & 6952.4 & 3795.6 & 7632.6 & 66.4 & 8075.5 & 9085.4 & 6036.8 \\
$\mathbf{1 1}$ & 25 & 40 & 20 & 99.7 & 6895.7 & 3783.7 & 7609.5 & 65.9 & 8019.6 & 9073.5 & 5935.2 \\
\hline
\end{tabular}

close to the maximal values under conditions No. 1 to No. 9. Therefore, the optimal ultrasonic extraction conditions were as follows: the extraction time was 30 $\mathrm{min}$, the volume of extraction solvent was $20 \mathrm{ml}$, and the extraction temperature was $40^{\circ} \mathrm{C}$.

Eight positive samples were ultrasonically extracted under such optimal conditions, using methanol, ethanol, acetone, acetonitrile, dichloromethane, trichloromethane, t-butyl methyl ether, petroleum ether, acetone/n-hexane (1:1, $\mathrm{V} / \mathrm{V})$ and acetone/dichloromethane $(1: 1, \mathrm{~V} / \mathrm{V})$, respectively, as the extraction solvents and the results were shown in Table 4. For Samples 1, 6, 7 and 8, the extraction amounts reached the maximum values when using methanol as the extraction solvent. For Samples 2, 3 and 4, the extraction amounts reached the maximum values when using trichloromethane as the extraction solvent. For Sample 5, the extraction amount reached the maximum value when using ethanol as the extraction solvent. For all these eight positive samples, the extraction amount reached the maximum value or close to the maximum value, or at least reached alarger value when using methanol as the extraction solvent. Therefore, methanol was chosen as the extraction solvent taking all factors into consideration.

\subsection{Optimization of Chromatographic Separation and Mass Spectrometric Detection}

The qualitative analysis was carried out by the exact mass of quasi-molecular ion and the retention time. For example, the formula of OI is $\mathrm{C}_{11} \mathrm{H}_{19} \mathrm{NOS}$ and the theoretical exact mass of its quasi-molecular ion is $\mathrm{m} / \mathrm{z} 214.12601$. The full-scan mass spectrum of OI during the range from $\mathrm{m} / \mathrm{z} 210$ to $\mathrm{m} / \mathrm{z} 220$ was shown in Figure 1(a). There appeared a strong peak at $\mathrm{m} / \mathrm{z} 214.12580$. The quasi-molecular ion peak of OI was shown in Figure 1(b), with a resolution of 70,000. The 
Table 3. Analysis of the orthogonal experimental data.

\begin{tabular}{|c|c|c|c|c|}
\hline sample & & Factor A & Factor B & Factor C \\
\hline \multirow{5}{*}{ Sample 1} & $\mathrm{k} 1$ & 101.0 & 99.4 & 97.2 \\
\hline & $\mathrm{k} 2$ & 94.3 & 91.0 & 97.0 \\
\hline & $\mathrm{k} 3$ & 92.8 & 97.7 & 93.9 \\
\hline & Maximum gap & 8.2 & 8.4 & 3.3 \\
\hline & Optimal condition & & $\mathrm{A} 1 \mathrm{~B} 1 \mathrm{C} 1$ & \\
\hline \multirow{5}{*}{ Sample 2} & k1 & 6946.3 & 6854.4 & 6863.6 \\
\hline & k2 & 6775.6 & 6876.8 & 6826.7 \\
\hline & k3 & 6879.1 & 6869.8 & 6910.7 \\
\hline & Maximum gap & 170.7 & 22.4 & 84.0 \\
\hline & Optimal condition & & $\mathrm{A} 1 \mathrm{~B} 2 \mathrm{C} 3$ & \\
\hline \multirow{5}{*}{ Sample 3} & $\mathrm{k} 1$ & 3782.2 & 3729.8 & 3732.3 \\
\hline & $\mathrm{k} 2$ & 3685.2 & 3736.6 & 3713.2 \\
\hline & k3 & 3735.0 & 3736.0 & 3765.9 \\
\hline & Maximum gap & 97.0 & 6.8 & 52.7 \\
\hline & Optimal condition & & $\mathrm{A} 1 \mathrm{~B} 2 \mathrm{C} 3$ & \\
\hline \multirow{5}{*}{ Sample 4} & k1 & 7662.0 & 7578.7 & 7561.3 \\
\hline & k2 & 7502.7 & 7582.3 & 7551.1 \\
\hline & $\mathrm{k} 3$ & 7577.4 & 7581.1 & 7629.7 \\
\hline & Maximum gap & 159.3 & 3.6 & 78.6 \\
\hline & Optimal condition & & A1B2C3 & \\
\hline \multirow{5}{*}{ Sample 5} & k1 & 66.2 & 65.6 & 66.2 \\
\hline & k2 & 65.6 & 65.7 & 65.2 \\
\hline & k3 & 65.2 & 65.6 & 65.6 \\
\hline & Maximum gap & 1.0 & 0.1 & 1.0 \\
\hline & Optimal condition & & $\mathrm{A} 1 \mathrm{~B} 2 \mathrm{C} 1$ & \\
\hline \multirow{5}{*}{ Sample 6} & k1 & 7893.2 & 7904.2 & 7948.6 \\
\hline & $\mathrm{k} 2$ & 8025.7 & 7920.9 & 7870.8 \\
\hline & k3 & 7790.7 & 7884.5 & 7890.2 \\
\hline & Maximum gap & 235.0 & 36.4 & 77.8 \\
\hline & Optimal condition & & $\mathrm{A} 2 \mathrm{~B} 2 \mathrm{C} 1$ & \\
\hline \multirow{5}{*}{ Sample 7} & $\mathrm{k} 1$ & 8924.6 & 8934.1 & 8984.6 \\
\hline & $\mathrm{k} 2$ & 9072.1 & 8951.0 & 8898.5 \\
\hline & $\mathrm{k} 3$ & 8803.8 & 8915.4 & 8917.4 \\
\hline & Maximum gap & 268.3 & 35.6 & 86.1 \\
\hline & Optimal condition & & $\mathrm{A} 2 \mathrm{~B} 2 \mathrm{C} 1$ & \\
\hline \multirow{5}{*}{ Sample 8} & k1 & 5921.2 & 5943.3 & 6015.9 \\
\hline & $\mathrm{k} 2$ & 6009.6 & 5975.6 & 5919.0 \\
\hline & $\mathrm{k} 3$ & 5898.4 & 5910.3 & 5894.3 \\
\hline & Maximum gap & 111.2 & 65.3 & 121.6 \\
\hline & Optimal condition & & $\mathrm{A} 2 \mathrm{~B} 2 \mathrm{C} 1$ & \\
\hline
\end{tabular}


Table 4. The extraction effects of different solvents (mg/kg).

\begin{tabular}{lccccccccc}
\hline \multirow{2}{*}{ Extraction solvent } & Sample 1 & Sample 2 & Sample 3 & Sample 4 & Sample 5 & Sample 6 & Sample 7 & Sample 8 \\
\cline { 2 - 9 } & UV-327 & triclosan & triclosan & triclosan & PCMX & OI & OI & OI \\
\hline Methanol & 105.3 & 6952.4 & 3795.6 & 7632.6 & 66.4 & 8075.5 & 9085.4 & 6036.8 \\
Ethanol & 82.5 & 6363.6 & 3402.6 & 6802.7 & 76.5 & 6897.5 & 7932.6 & 5135.2 \\
Acetonitrile & 90.4 & 8827.6 & 4658.7 & 7133.2 & 19.8 & 3308.9 & 7575.2 & 2751.9 \\
Acetone & 88.6 & 6837.2 & 3699.8 & 7188.9 & 57.9 & 3672.2 & 8275.3 & 1346.7 \\
Dichloromethane & 70.3 & 13112.7 & 7048.7 & 13735.4 & 20.9 & 2602.5 & 6265.9 & 1175.6 \\
Trichloromethane & 37.1 & 15124.4 & 8149.6 & 18871.2 & 23.6 & 2365.8 & 5872.6 & 1352.4 \\
t-butyl methyl ether & 15.3 & 5486.2 & 2924.4 & 7757.6 & 29.8 & 2129.6 & 5361.2 & 424.2 \\
Petroleum ether & 16.4 & 4956.4 & 2662.7 & 6962.3 & 24.5 & 3318.6 & 6858.4 & 1516.2 \\
Acetone/n-hexane (1:1, V/V) & 80.1 & 7175.3 & 3845.3 & 6862.7 & 53.2 & 3462.8 & 7654.9 & 1736.5 \\
Acetone/dichloromethane (1:1, V/V) & 88.2 & 7068.5 & 3812.5 & 7132.8 & 60.1 & 3556.3 & 7419.5 & 1548.9 \\
\hline
\end{tabular}
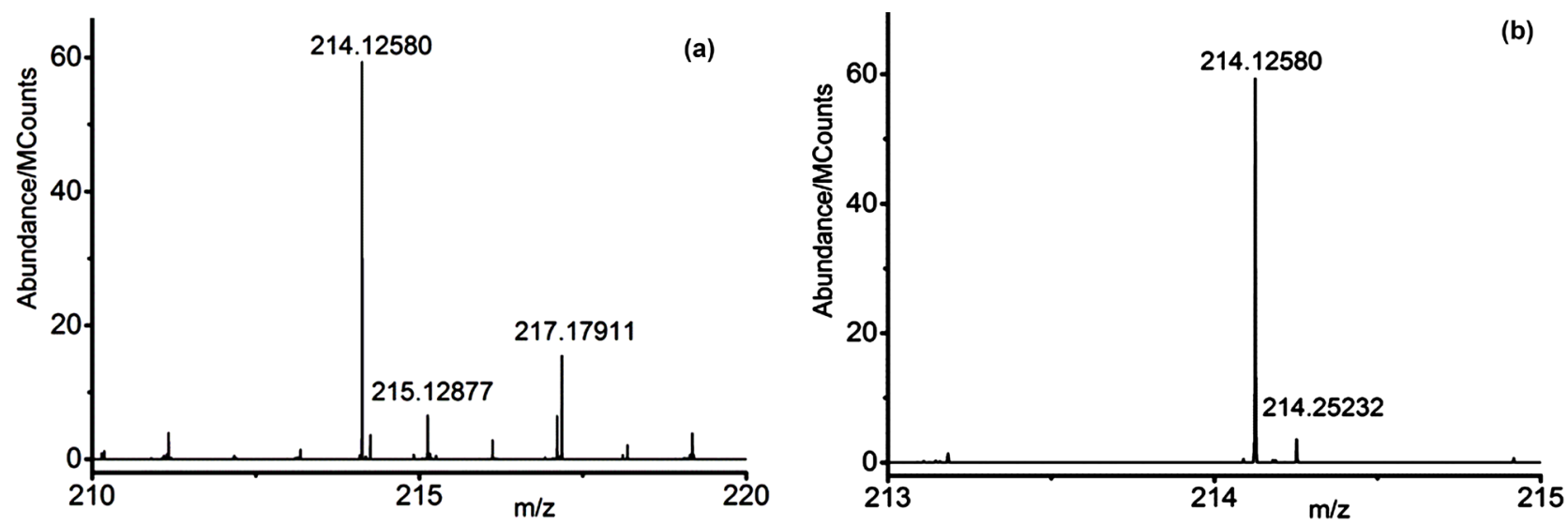

Figure 1. (a) Full-scan mass spectrum and (b) quasi-molecular ion peak $(\mathrm{R}=70000)$ of OI.

ion extraction window of the quasi-molecular ion was $5 \mathrm{ppm}$, that is to say, the ion extraction window varied from $\mathrm{m} / \mathrm{z} 214.12494$ to $\mathrm{m} / \mathrm{z} 214.12708$. Only one peak at $\mathrm{m} / \mathrm{z} 214.12580$ met this requirement. In another way, the peak at $\mathrm{m} / \mathrm{z}$ 214.12580 was the quasi-molecular ion of OI. Therefore, this compound could be confirmed as OI according to the retention time and corresponding quasi-molecular ion. The other thirteen target compounds might be confirmed according to the same method.

Two mobile phases such as methanol/water and acetonitrile/water were usually used in LC/MS analysis, and appropriate formic aid was added into water to promote ionization, to enhance the peak intensity and improve the peak shape [48]. It had been found by the comparative experiments that there existed better separation among the target compounds when using acetonitrile/water system as the mobile phase. On the other hand, the intensity of each target compounds increased significantly when using methanol/water system as the mobile phase. Similar phenomena were observed in literature [49]. Baseline separation is not necessary when UPLC/Orbitrap HRMS technique was applied in 
the quantitative analysis. Therefore, methanol/water system was chosen as the mobile phase. The peak area and peak shape of the extracted ions were observed when changing the content of formic acid in the range of $0.05 \%-1.00 \%$. The results demonstrated that the peak area of these extracted ions all reached the maximum when $0.1 \%$ formic acid added into water. At the same time, the peak of the extracted ions was sharp and symmetric. A certain concentration of ammonium acetate could significantly increase the peak responses of quasi-molecular ion $[\mathrm{M}+\mathrm{H}]^{+}$. Ammonium acetate of various concentrations in the range of 2 to $10 \mathrm{mmol} / \mathrm{l}$ were added into the mobile phase to observe the change of the peak area in extracted chromatogram. The results showed that the peak area in the chromatographic measurement increased significantly when $5 \mathrm{mmol} / \mathrm{l}$ ammonium acetate was used. Therefore, the mobile phase was at last determined as methanol/0.1\% aqueous formic acid solution containing $5 \mathrm{mmol} / \mathrm{l}$ ammonium acetate.

To achieve the best separation, a series of trials were performed on the original composition of the mobile phase and the gradient of elution and the determined separation conditions were shown in segment 2.3. The UPLC/Orbitrap HRMS analysis of the standard mixture solution of fourteen target compounds was performed during nine minutes. Triclosan and PCMX were detected in ESI negative mode while the other twelve target compounds were all detected in ESI positive mode. Figure 2 showed the UPLC/Orbitrap HRMS chromatograms of fourteen target compounds, in which the retention time of DCOI and UV-P, UV-327 and UV-328, UV-320 and UV-326 were the same, respectively, and could not be distinguished from each other.

Chromatograms of fourteen target compounds were extracted based on the theoretical exact mass of quasi-molecular ion in positive or negative mode and the extraction window was all $5 \mathrm{ppm}$. Therefore, the retention time of each target compounds was determined. Extracted ion chromatograms of fourteen target compounds were shown in Figure 3 and all target compounds displayed a sharp peak shape. For each of fourteen target compounds, the detected exact mass was obtained from the extracted ion chromatogram and the mass accuracy between theoretical exact mass and detected exact mass was all lower than $2 \mathrm{ppm}$. As to
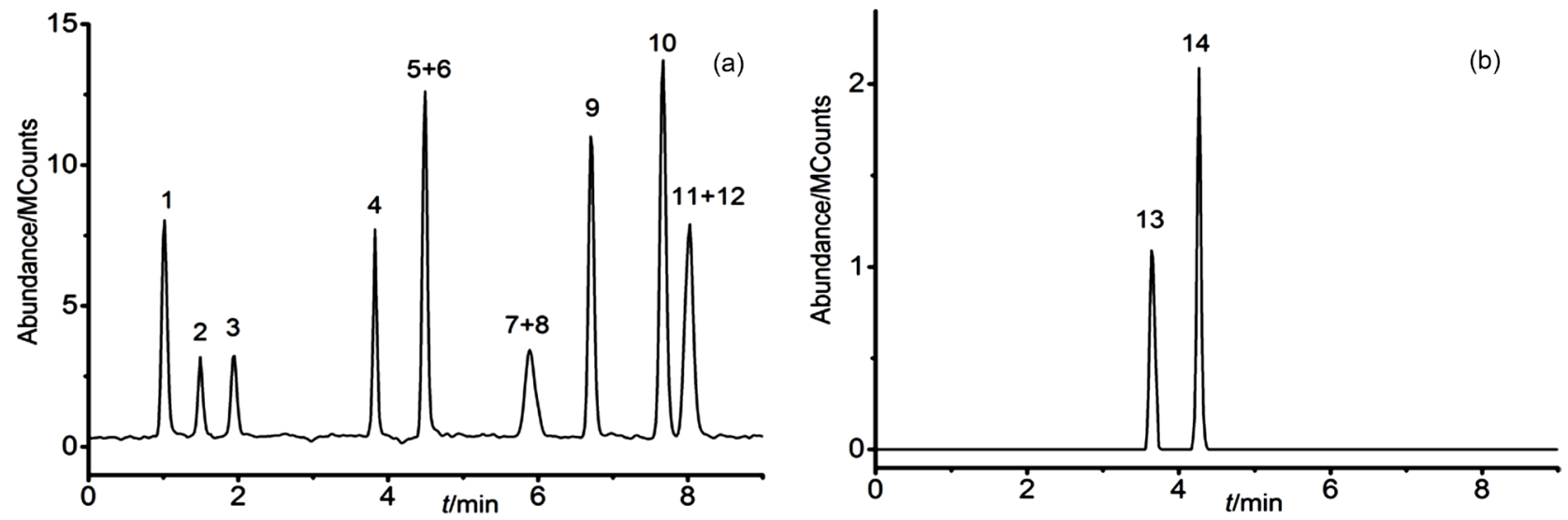

Figure 2. UPLC/Orbitrap HRMS chromatograms of fourteen target compounds; Peaks 1: MI; 2: CMI; 3: BIT; 4: OI; 5: DCOI; 6: UV-P; 7: UV-328; 8: UV-327; 9: UV-329; 10: UV-350; 11: UV-326; 12: UV-320; 13: PCMX; 14: triclosan. 

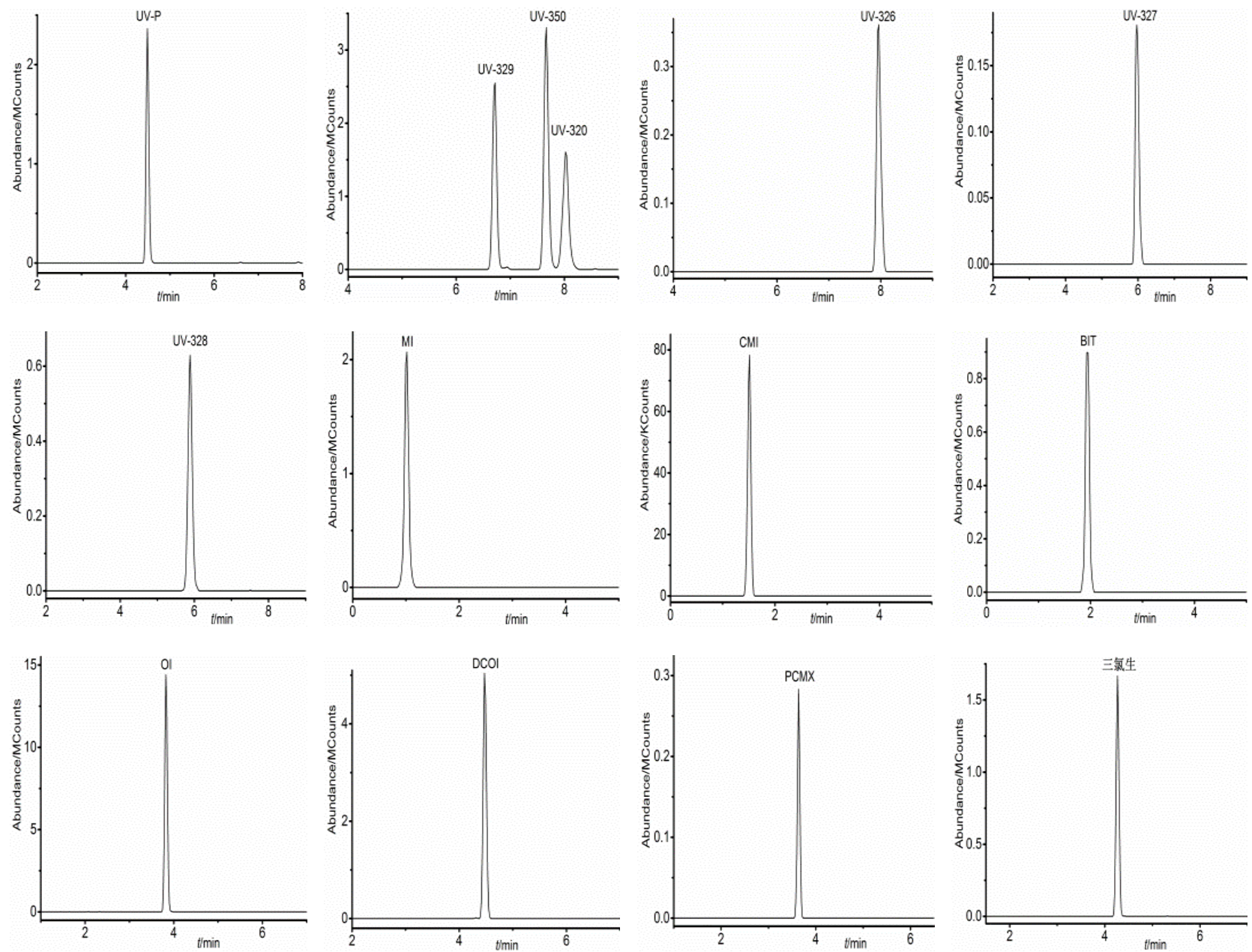

Figure 3. Extracted ion chromatograms of fourteen target compounds in the mixed standard solution.

an unknown sample, qualitative analysis could be performed according to the retention time and the detected exact mass of extracted ion. Obviously, the extracted ion chromatograms of DCOI distinguished completely from that of UV-P. Similar phenomena occurred between UV-327 and UV-328, UV-320 and UV-326, respectively. Quantitative analysis was carried out by the peak area in extracted chromatogram, therefore, overlapping between DCOI and UV-P, UV-327 and UV-328, UV-320 and UV-326, respectively, did not affect the accuracy of quantification.

\subsection{Method Validation}

A validation was performed and several parameters such as linearity, matrix effect, limit of detection (LOD), spiked recovery and precision were studied. The obtained results were shown in Table 5 and Table 6, respectively.

In order to evaluate the linearity, mixed standard solutions of fourteen target compounds were investigated. The calibration curve was based on the peak area in extracted chromatogram versus concentration. As a result, all standards exhibited a good linearity in its own linear range and the correlation coefficients all larger than 0.998 . 
Table 5. Linear relationship and limits of detection.

\begin{tabular}{|c|c|c|c|c|c|c|}
\hline No. & Compound & Retention time/min & Linear range $/(\mu \mathrm{g} / \mathrm{L})$ & Linear equation & $\mathbf{r}$ & $\mathrm{LOD} /(\mu \mathrm{g} / \mathrm{kg})$ \\
\hline 1 & MI & 0.998 & $0.2 \sim 96.9$ & $A=469186 \rho+384256$ & 0.99995 & 0.1 \\
\hline 2 & CMI & 1.495 & $0.2 \sim 97.1$ & $A=505528 \rho-387302$ & 0.99870 & 0.1 \\
\hline 3 & BIT & 1.931 & $0.2 \sim 96.3$ & $A=194971 \rho+741555$ & 0.99935 & 0.1 \\
\hline 4 & PCMX & 3.638 & $0.4 \sim 160.0$ & $A=497490 \rho-61409$ & 0.99880 & 0.2 \\
\hline 5 & OI & 3.804 & $0.2 \sim 97.2$ & $A=250749 \rho+196053$ & 0.99995 & 0.1 \\
\hline 6 & triclosan & 4.269 & $0.2 \sim 80.0$ & $A=187946 \rho-68682$ & 0.99995 & 0.1 \\
\hline 7 & DCOI & 4.478 & $0.2 \sim 97.9$ & $A=898127 \rho-196549$ & 0.99995 & 0.1 \\
\hline 8 & UV-P & 4.498 & $0.2 \sim 82.0$ & $A=244195 \rho+31133$ & 0.99955 & 0.1 \\
\hline 9 & UV-328 & 5.991 & $0.5 \sim 212.0$ & $A=101599 \rho+352068$ & 0.99880 & 0.3 \\
\hline 10 & UV-327 & 6.091 & $0.4 \sim 172.0$ & $A=44067 \rho-503735$ & 0.99910 & 0.2 \\
\hline 11 & UV-329 & 6.722 & $0.4 \sim 156.0$ & $A=480200 \rho-170370$ & 0.99990 & 0.2 \\
\hline 12 & UV-350 & 7.669 & $0.2 \sim 82.4$ & $A=513061 \rho-715854$ & 0.99985 & 0.1 \\
\hline 13 & UV-326 & 7.984 & $0.5 \sim 184.0$ & $A=73524 \rho-575063$ & 0.99985 & 0.3 \\
\hline 14 & UV-320 & 8.043 & $0.5 \sim 208.0$ & $A=262936 \rho+70072$ & 0.99955 & 0.3 \\
\hline
\end{tabular}

Matrix effects were expressed as the matrix-matched calibration slope to solvent calibration ratio in the whole calibration range. Blank textiles were extracted and diluted with different dilution factors such as 1200, 3000 and 6000, and then a series of matrix-matched standards of fourteen target compounds were prepared with the blank extracts mentioned above. The results showed that the matrix effects of fourteen target compounds in three different dilution factors, ranging from $97 \%$ to $109 \%$, were not significant and could be neglected. To obtain a better sensitivity, this work chose 1200 as the dilution factor for the textiles.

Previous studies have typically calculated LOD as the concentration level as a signal-to-noise ratio of $3(\mathrm{~S} / \mathrm{N}=3)$, regardless of the low noise level of ion chromatograms extracted by high resolution mass spectrometry (HRMS) with a mass extraction window of $\pm 5 \mathrm{ppm}$. Therefore, the establishment of an LOD based on $\mathrm{S} / \mathrm{N}$ value was not realistically feasible. This work used an alternative approach to estimate the LOD, that is to say, matrix-matched standard solutions were diluted successively to obtain the lowest concentration that could be repeatedly determined with a low RSD value during a longer time period. The LOD values of fourteen target compounds varied from 0.1 to $0.3 \mu \mathrm{g} / \mathrm{kg}$. RSD values calculated from six repeated injections at the LOD level were as low as $3.5 \%-11.7 \%$. The retention time, linear range, linear equation, correlation coefficient, and LOD of fourteen target compounds are shown in Table 5.

Recoveries were evaluated at three different spiked concentration levels as shown in Table 6. The spiked blank samples were analyzed using the established method and nine parallel assays were also carried out. Recoveries at three spiked levels ranged from $80.5 \%$ to $96.3 \%$ while the relative standard deviation (RSD) varied from $3.2 \%$ to $9.9 \%$. 
Table 6. Recoveries of fourteen target compounds in three different kinds of blank textiles $(n=9)$.

\begin{tabular}{|c|c|c|c|c|c|c|c|}
\hline \multirow{2}{*}{ Compound } & \multirow{2}{*}{$\begin{array}{r}\text { Spiked } \\
(\mu \mathrm{g} / \mathrm{kg})\end{array}$} & \multicolumn{2}{|c|}{ cotton } & \multicolumn{2}{|c|}{ polyester } & \multicolumn{2}{|c|}{ Cotton/polyester blended fiber } \\
\hline & & Recovery/\% & $\mathrm{RSD} / \%$ & Recovery/\% & $\mathrm{RSD} / \%$ & Recovery/\% & $\mathrm{RSD} / \%$ \\
\hline \multirow{3}{*}{ MI } & 0.2 & 84.6 & 7.2 & 86.3 & 6.7 & 85.7 & 7.4 \\
\hline & 1.2 & 90.1 & 5.3 & 93.5 & 4.9 & 92.8 & 5.5 \\
\hline & 4.8 & 90.2 & 5.9 & 94.3 & 4.7 & 94.8 & 4.9 \\
\hline \multirow{3}{*}{ CMI } & 0.2 & 81.6 & 9.1 & 80.7 & 9.3 & 82.3 & 8.9 \\
\hline & 1.2 & 83.7 & 6.4 & 84.6 & 6.7 & 84.3 & 5.8 \\
\hline & 4.9 & 91.2 & 5.8 & 94.5 & 5.5 & 92.7 & 6.3 \\
\hline \multirow{3}{*}{ BIT } & 0.2 & 81.3 & 9.2 & 82.3 & 8.7 & 81.9 & 8.9 \\
\hline & 1.2 & 83.6 & 5.5 & 85.3 & 5.6 & 84.5 & 6.1 \\
\hline & 4.8 & 92.4 & 5.3 & 94.5 & 4.9 & 93.8 & 5.7 \\
\hline \multirow{3}{*}{ PCMX } & 0.4 & 81.2 & 7.3 & 80.5 & 8.4 & 81.9 & 7.4 \\
\hline & 2.0 & 82.0 & 8.2 & 84.3 & 6.8 & 84.5 & 7.3 \\
\hline & 8.0 & 89.0 & 4.0 & 90.5 & 4.3 & 91.2 & 3.8 \\
\hline \multirow{3}{*}{ OI } & 0.2 & 82.0 & 6.9 & 83.4 & 6.4 & 82.7 & 7.2 \\
\hline & 1.2 & 85.4 & 5.7 & 84.9 & 6.3 & 86.3 & 5.2 \\
\hline & 4.9 & 92.6 & 4.0 & 94.8 & 3.2 & 93.7 & 4.5 \\
\hline \multirow{3}{*}{ triclosan } & 0.2 & 84.0 & 6.8 & 86.4 & 6.5 & 85.7 & 5.9 \\
\hline & 1.0 & 86.8 & 7.0 & 88.5 & 7.2 & 87.8 & 6.4 \\
\hline & 4.0 & 94.1 & 4.6 & 96.3 & 4.2 & 95.4 & 5.3 \\
\hline \multirow{3}{*}{ DCOI } & 0.2 & 82.2 & 9.8 & 81.9 & 9.9 & 83.5 & 8.7 \\
\hline & 1.2 & 82.1 & 6.3 & 84.3 & 6.5 & 83.8 & 5.7 \\
\hline & 4.9 & 91.0 & 5.5 & 93.2 & 4.8 & 92.7 & 5.9 \\
\hline \multirow{3}{*}{ UV-P } & 0.2 & 82.7 & 7.0 & 84.2 & 6.7 & 83.5 & 7.1 \\
\hline & 1.0 & 87.3 & 5.0 & 88.9 & 4.3 & 87.6 & 5.4 \\
\hline & 4.1 & 92.8 & 3.6 & 93.7 & 3.3 & 93.5 & 3.8 \\
\hline \multirow{3}{*}{ UV-328 } & 0.5 & 82.2 & 7.7 & 83.6 & 7.2 & 83.1 & 7.9 \\
\hline & 2.7 & 82.8 & 7.5 & 85.3 & 6.9 & 84.5 & 7.2 \\
\hline & 10.6 & 93.6 & 4.7 & 95.8 & 3.7 & 94.3 & 4.5 \\
\hline \multirow{3}{*}{ UV-327 } & 0.4 & 81.2 & 8.6 & 80.7 & 9.5 & 81.9 & 8.3 \\
\hline & 2.2 & 83.6 & 8.3 & 85.5 & 8.7 & 84.6 & 8.2 \\
\hline & 8.6 & 91.4 & 4.8 & 93.5 & 4.2 & 92.9 & 5.3 \\
\hline \multirow{3}{*}{ UV-329 } & 0.4 & 82.4 & 6.9 & 84.6 & 6.1 & 83.9 & 6.5 \\
\hline & 2.0 & 87.4 & 6.4 & 90.5 & 5.4 & 89.7 & 5.9 \\
\hline & 7.8 & 91.7 & 6.1 & 94.2 & 5.6 & 93.5 & 5.8 \\
\hline \multirow{3}{*}{ UV-350 } & 0.2 & 81.1 & 7.3 & 83.6 & 6.8 & 82.9 & 7.1 \\
\hline & 1.0 & 83.6 & 6.3 & 86.7 & 4.9 & 87.2 & 4.3 \\
\hline & 4.1 & 90.2 & 5.7 & 94.5 & 4.1 & 92.8 & 5.9 \\
\hline \multirow{3}{*}{ UV-326 } & 0.5 & 80.9 & 6.6 & 83.2 & 6.3 & 82.7 & 6.9 \\
\hline & 2.3 & 81.5 & 7.2 & 83.1 & 6.5 & 82.8 & 7.3 \\
\hline & 9.2 & 92.2 & 4.7 & 94.6 & 3.2 & 93.8 & 4.1 \\
\hline \multirow{3}{*}{ UV-320 } & 0.5 & 81.4 & 8.4 & 80.5 & 9.7 & 82.1 & 9.2 \\
\hline & 2.6 & 82.3 & 6.0 & 84.2 & 5.5 & 83.7 & 5.9 \\
\hline & 10.4 & 90.8 & 4.9 & 92.1 & 4.3 & 92.7 & 4.5 \\
\hline
\end{tabular}


The method precision was assessed by repeatability and reproducibility studies, expressed as the percent relative standard deviation (RSD\%). Repeatability was assessed by the recovery study and values were shown in Table 6 . Reproducibility was carried out by extracting and analyzing a positive textile sample available commercially containing $295.4 \mathrm{mg} / \mathrm{kgOI}$ in nine different laboratories. Replicate $(\mathrm{n}=2)$ samples were run in each laboratory and the RSD\% value ( $\mathrm{n}=$ 18) was calculated for nine laboratories, which the RSDs were within $1.5 \%$.

\subsection{Analyses of These Compounds in the Commercial Samples}

The high mass accuracy and full-scan data of the Orbitrap HRMS allow the developed method to assess virtually all of the compounds present in a sample. 387 textile samples available commercially were analyzed using the established method. The analysis results showed that different target compounds at various content levels were detected in sixteen samples as shown in Table 7. The UPLC/Orbitrap HRMS chromatogram of a positive sample was shown in Figure 4(a), in which a sharp peak appeared at $6.087 \mathrm{~min}$, nearly close to the retention time of UV-327 $\left(t_{R}=6.091 \mathrm{~min}\right)$. The corresponding full-scan mass spectrometry was shown in Figure 4(b), in which only the region from m/z 357 to m/z 359 was demonstrated. The theoretical exact mass of UV-327 was m/z 358.16807 and its extracted ion window was $5 \mathrm{ppm}$, that is to say, from $\mathrm{m} / \mathrm{z} 358.16628$ to $\mathrm{m} / \mathrm{z}$ 358.16986 . Only one peak appeared at $\mathrm{m} / \mathrm{z} 358.16745$ in this region and the error of the accuracy between this peak and the theoretical exact mass of UV-327 was $-1.73 \mathrm{ppm}$. Therefore, this peak was the quasi-molecular ion of UV-327. UV327 was proved to exist in this positive sample according the retention time and the detected exact mass of the quasi-molecular ion.

Table 7. Analysis results of real samples.

\begin{tabular}{cll}
\hline No. & \multicolumn{1}{c}{ Sample } & \multicolumn{1}{c}{ Detected $/(\mathbf{m g} / \mathbf{k g})$} \\
\hline 1 & White cotton cloth & UV-327 105.3 \\
2 & Army green woven polyester fabric & triclosan 6952.4 \\
3 & White woven cotton fabric & triclosan 7632.6 \\
4 & Beige woven polyester fabric & triclosan3795.6 \\
5 & Yellow cotton lace & triclosan 4.2 \\
6 & White silk lace & triclosan 2.0 \\
7 & Printed silkworm silk & PCMX 66.4 \\
8 & Colour gingham & PCMX 1105.5 \\
9 & Blue gingham & PCMX 6.2 \\
10 & Rose knitted cotton T-shirt & PCMX 325.9 \\
11 & Woven silk dress & OI 6036.8 \\
12 & Woven linen women's long-sleeved shirt & OI 295.4 \\
13 & Plain woven dyeing women cotton top & OI 9085.5 \\
14 & Ms long-sleeved silk knitted pullover & OI 661.7 \\
15 & Women's cotton short-sleeved shirt & OI 713.2 \\
16 & Woven linen men's shirt & OI 8075.5 \\
\hline
\end{tabular}



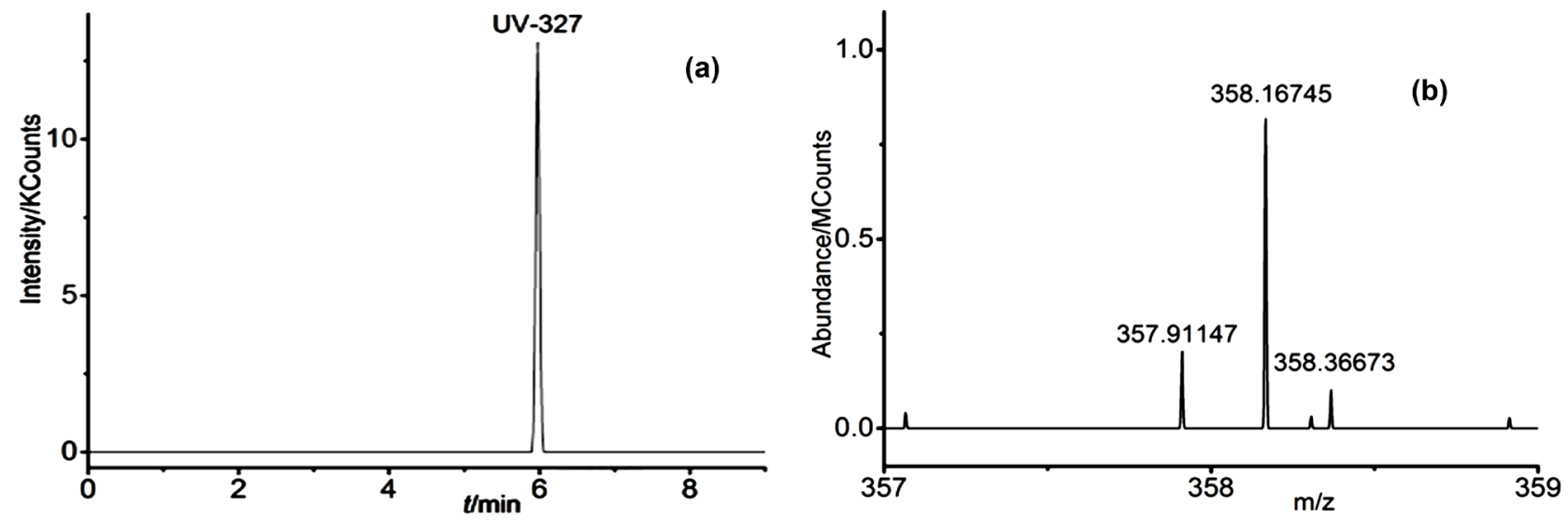

Figure 4. (a) UPLC/MS chromatogram and (b) full-scan mass spectrum of a real sample.

\section{Conclusion}

The present study established a new approach for the simultaneous determination of the contents of seven benzotriazole ultraviolet absorbers and seven antibacterial agents in textile samples based on UPLC/Orbitrap HRMS system. The results showed that the present method provided good limits of detection, precision and accuracy in the quantification of these ultraviolet absorber and antibacterial agent compounds. The applicability of the present method was also demonstrated by the analysis of 387 textile samples from commercial sources.

\section{Acknowledgements}

The authors appreciate the support from the General Administration of Quality Supervision, Inspection and Quantine (AQSIQ) Science and Technology planning project (Grant No. 2014IK163). The authors are also grateful to Professor Xinsheng Chai for insightful suggestions and language revision.

\section{References}

[1] Aultz, D.E. (1996) Development on Polymeric Benzotriazole Stabilizer. Spec. Chem., $16,71,73-74$.

[2] Reihardi, E., Waeber, R., Niederer, M., Mauer, T., Maly, H. and Scherer, S. (2001) Preservation of Products with MCI/MI in Switzerland. Contact Dermatit., 45, 257 264. https://doi.org/10.1034/j.1600-0536.2001.450501.x

[3] Tsatsaroni, E.G. and Eleftheriadis, I.C. (2004) UV-Absorbers in the Dyeing of Polyester with Disperse Dyes. Dyes Pigments, 61, 141-147. https://doi.org/10.1016/j.dyepig.2003.10.002

[4] An, Q.F., Wang, Y., Lu, D.S., Huang, L.X. and Wang, Q.J. (2007) Recent Progress of Ultraviolet Ray-Proofing Finishing Agent for Fabric. Chem. Ind. \& Eng. Prog., 26, 819-824.

[5] Liu, Y.Y., Gao, Q.W., Zhu, Q., et al. (2008) Synthesis and Application of Reactive Isothiazolone Antibacterial agent. Prog. Text. Sci. Technol., No. 6, 17-19.

[6] Li, S.C. and Tang, C.B. (2009) Antibacterial Finishing of Isothiazolinone Resins to Silk Fabric. Silk, No. 9, 29-31.

[7] Liu, Y.Y., Kong, L.H., Zhu, Q., et al. (2009) Synthesis and Application of Reactive 
Isothiazolone Antibacterial agent. Text. Auxiliaries, 26, 15-18.

[8] Xia, S., Wang, Z., Yang, J.Q., Hao, L.M. and Wu, J.H. (2009) Structure and Properties of Electronspun Antibacterial Polyurethane Nano Fibers. Chin. Synthetic Fiber Industry, 32, 28-30.

[9] Hirata-Koizumi, M., Matsuyama, T., Imai, T., Hirose, A., Kamata, E. and Ema, M. (2009) Disappearance of Gender-Related Difference in the Toxicity of Benzotriazole Ultraviolet Absorber in Juvenile Rats. Conqenit. Anom., 49, 247-252. https://doi.org/10.1111/j.1741-4520.2009.00248.x

[10] Morley, J.O., Oliver, A.J. and Charlton, M.H. (1998) Theoretical Studies on the Biocidal Activity of 5-Chloro-3-Isothiazolone. J. Mol. Struct: Theochem., 429, 103-110. https://doi.org/10.1016/S0166-1280(97)00342-4

[11] Li, H., Zhou, J., Shi, R. and Chen, W.Y. (2011) Identification of Fungi from Children's Shoes and Application of a Novel Antimicrobial Agent on Shoe Insole. Afr. J. Biotechnol., 10, 14493-14497. https://doi.org/10.5897/AJB11.2160

[12] Ema, M., Fukunishi, K., Hirose, A., Hirata-Koizumi, M., Matsumoto, M. and Kamata, E. (2008) Repeated-Dosed and Reproductive Toxicity of the Ultraviolet Absorber 2-(3',5'-di-tert-butyl-2'-Hydroxyphenyl)-5-Chlorobenzotriazole in Rate. Drug Chem. Toxicol., 31, 399-412. https://doi.org/10.1080/01480540802171282

[13] Nakata, H., Murata, S. and Filatreau, J. (2009) Occurrence and Concentrations of Benzotriazole UV Stabilizers in Marine Organisms and Sediments from the Ariake Sea, Japan. Environ. Sci. Technol., 43, 6920-6926. https://doi.org/10.1021/es900939j

[14] Kim, J.W., Chang, K.H., Isobe, T. and Tanabe, S. (2011) Acute Toxicity of Benzotriazole Ultraviolet Stabilizers on Freshwater Crustacean (Daphnia pulex). J. Toxicol. Sci., 36, 247-251. https://doi.org/10.2131/jts.36.247

[15] Nakata, H., Shinohara, R.I., Nakazawa, Y., et al. (2012) Asia-Pacific Mussel Watch for Emerging Pollutants: Distribution of Synthetic Musks and Benzotriazole UV Stabilizers in Asia and US Coastal Water. Mar. Pollut Bull, 64, 2211-2218. https://doi.org/10.1016/j.marpolbul.2012.07.049

[16] Podmore, P. (1998) An Epidemic of Isothiazolinone Sensitization in a Flax Spinning Mill. Contact Dermatit., 38, 165-166. https://doi.org/10.1111/j.1600-0536.1998.tb05687.x

[17] Basketter, D.A., Rodford, R., Kimber, I., Smith, I. and Wahlberg, J.E. (1999) Skin Sensitization Risk Assessment: A Comparative Evaluation of 3 Isothiazolinone Biocides. Contact Dermatit., 40, 150-154. https://doi.org/10.1111/j.1600-0536.1999.tb06013.x

[18] Fewings, J. and Menne, T. (1999) An Update of the Risk Assessment for Methylchloroisothiazolinone/Methylisothiamlinone (MCI/MI) with Focus on Rinse-Off Products. Contact Dermatit., 41, 1-13. https://doi.org/10.1111/j.1600-0536.1999.tb06200.x

[19] Hahn, S., Schnerder, K., Gartiser, S., Heger, W. and Mangelsdorf, I. 2010 Consumer Exposure to Biocides-Identification of Relevant Sources and Evaluation of Possible Health Effects. Environ. Health, 9, 1-11.

[20] Ackermann, L., Aalto-Korte, K., Alanko, K., Hasan, T. and Jolanki, R. (2011) Contact Sensitization to Methylisothiazolinone in Finland-A Multicentre Study. Contact Dermatit., 64, 49-53. https://doi.org/10.1111/j.1600-0536.2010.01811.x

[21] Momma, J., Takada, K. and Aida, Y. (1988) Combined Long-Term Toxicity and Carcinogenicity Test of P-Chloro-M-Xylenol (PCMX) Applied to Female Mouse Skin. Eisei Shikenjo Hokoku, 106, 39-47.

[22] Yamano, T., Shimizu, M. and Noda, T. (2003) Allergenicity Evaluation of P-Chlo- 
ro-M-Cresol and P-Chloro-M-Xylenol by Non-Radioactive Murine Local LymphNode Assay and Multiple-Dose Guinea Pig Maximization Test. Toxicol., 190, 259266. https://doi.org/10.1016/S0300-483X(03)00161-6

[23] (2012) Regulation (EU) No. 528/2012 of the European Parliament and of the Council of 22 May 2012 Concerning the Making Available on the Market and Use of Biocidal Products. Off. J. Eur. Union, L167, 1-123.

[24] EN 71-9-2005: Safety of Toys-Part 9: Organic Chemical Compounds-Requirement.

[25] Claudia, C., Carmela, C., Robertro, L.G., et al. (2005) Application of Methods for Assessing the Geno- and Cytotoxicity of Triclosan to C. ehrenbergii. J. Hazard. Mat., 122, 227-232. https://doi.org/10.1016/j.jhazmat.2005.03.002

[26] (2002) Commission Directive 2002/72/EC of 6 August 2002 Relating to Plastic Materials and Articles Intended to Come into Contact with Foodstuffs. Off. J. Eur. Commun., 15, 18-58.

[27] Oeko-Text Standard 100 (2016 Edition).

[28] Nakata, H., Shinohara, R.I., Murata, S., Watanabe, M. (2010) Detection of Benzotriazole UV Stabilizers in the Blubber of Marine Mammals by Gas Chromatography-High Resolution Mass Spectrometry (GC-HRMS). J. Environ. Monit., 12, 20882092. https://doi.org/10.1039/c0em00170h

[29] Kim, J.W., Isobe, T., Malarvannan, G., Sudaryanto, A., Chang, K.H., Prudente, M. and Tanabe, S. (2012) Contamination of Benzotriazole Ultraviolet Stabilizers in House Dust from the Philippines: Implications on Human Exposure. Sci. Total Environ., 424, 174-181. https://doi.org/10.1016/j.scitotenv.2012.02.040

[30] Wang, H.C., Zhang, H.J. and Chen, J.P. (2013) Simultaneous Determination of Benzotriazoles and Benzothiazoles in Surface Water by Solid Phase Extraction and High Performance Liquid Chromatography-Tandem Mass Spectrometry. J. Instrum. Anal., 32, 1056-1061.

[31] Tian, X.X., Zhu, Z.J., Guo, H., et al. (2014) Determination of Benzotriazole Ultraviolet Absorber in Textiles by HPLC MS/MS. Dyeing \& Finishing, 40, 40-43.

[32] Wang, C.Y., Liao, W.Z., Shi, Q.Y., Bai, S. and Xie, T.T. (2016) Determination of Seven Benzotriazole Ultraviolet Absorbers in Textiles. J. Shenzhen Univ. Sci. Engineer., 33, 324-330. https://doi.org/10.3724/SP.J.1249.2016.03324

[33] Wang, C.Y., Lin, J.F., Xie, T.T., Tang, L.C. and Zhu, N.Q. (2016) Determination of Six Kinds of Benzotriazole of Ultraviolet Absorbent in Textiles by Ultra High Performance Liquid Chromatography. Text. Dyeing Finishing J., 38, 50-53.

[34] Wang, C.Y., Tang, L.C., Lin, J.F. and Zhong, S.Y. (2016) Simultaneous Determination of Six Benzotriazole Ultraviolet Absorbers in Textiles by UPLC Coupled with Ultrasonic Extraction. Dyeing \& Finishing, 42, 40-43.

[35] Wang, C.Y., Xie, T.T., Yang, Z.J., Liu, C.M. and Li, L.X. (2010) Determination of Triclosan in Textiles by Ultra Performance Liquid Chromatography. J. Instrum. Anal., 29, 1231-1234.

[36] Wang, C.Y., Wu, T.M., Yang, Z.J., Xie, T.T., Liu, C.M. and Li, L.X. (2011) Determination of Triclosan in Textiles by Gas Chromatography Coupled with Ultrasonic Extraction. J. Anal. Sci., 27, 507-509.

[37] Wang, C.Y., Zhang, W.Y., Xie, T.T., Liu, C.M., Li, L.X. and Gong, Y.Q. (2011) Determination of Triclosan in Antibacterial Textiles Using Gas Chromatography-Mass Spectrometry. Tech. Text., No. 2, 45-48.

[38] Wang, C.Y., Xie, T.T., Zhang, W.Y., Tang, L.C., Liu, C.M. and Li, L.X. (2011) Determination of Triclosan in Antibacterial Fabrics Using GC/MS/MS Combined with 
Microwave-Assisted Extraction. Dyeing \& Finishing, 39, 32-35.

[39] Chen, J.Q. (2013) Study on Determination the Content of Triclosan in Textiles by the Method of Liquid Chromatography (HPLC)-Mass Spectrometry. Chin. Fiber Insp., No. 10, 74-76.

[40] Lu, C.M., Mou, J., Zhou, B.Y., Zhang, X.Y. and Li, M.X. (2014) Survey Analysis of Triclosan in Textiles by Liquid Chromatography-Tandem Mass Spectrometry. J. Text. Res., 35, 87-90.

[41] Xie, T.T., Wang, C.Y., Lin, J.F., Shen, Y.L., Li, Y.H. and Zhu, N.Q. (2016) Rapid Determination of Five Kinds of Isothiazolinones Antibacterial Agents in Textiles by UPLC. Anal. Instrum., No. 3, 32-37.

[42] Speksnijder, P., van Ravestin, J. and de Voogt, P. (2010) Trace Analysis of Isothiazolinones in Water Samples by Large-Volume Direct Injection Liquid Chromatography Tandem Mass Spectrometry. J. Chromatogr. A, 1217, 5184-5189. https://doi.org/10.1016/j.chroma.2010.06.010

[43] Lin, Q.B., Wang, T.J., Song, H. and Li, B. (2010) Analysis of Isothiazolinone Biocides in Paper for Food Packaging by Ultra-High-Performance Liquid ChromatographyTandem Mass Spectrometry. Food Addit. Contam., 27, 1775-1781. https://doi.org/10.1080/19440049.2010.521896

[44] Yang, R.J., Wei, B.W., Yu, W.J., Gao, H. and Sun, X.J. (2011) Determination of 3 Isothiazolinone Preservatives in Toys Using Liquid Chromatography-Tandem Mass Spectrometry. Chin. J. Chromatogr., 29, 513-516.

https://doi.org/10.3724/SP.J.1123.2011.00513

[45] Wei, W.H. and Deng, S.P. (2011) Determination of PCMX in Disinfectant and Health Nursing Product by HPLC. Chin. J. Health Lab. Technol., 21, 323-324.

[46] Zhang, L., Luo, X., Niu, Z.Y., Ye, X.W., Tang, Z.X. and Yao, P. (2015) Rapid Screening and Identification of Multi-Class Substances of Very High Concern in Textiles Using Liquid Chromatography-Hybrid Linear Ion Trap Orbitrap Mass Spectrometry. J. Chromatogr. A, 1386, 22-30. https://doi.org/10.1016/j.chroma.2015.01.077

[47] Wang, C.Y., Zhu, N.Q., Lin, J.F., Tang, L.C. and Yang, Z.S. (2016) Test of Benzotriazole Ultraviolet Light Absorbers in Textiles. Cotton Text. Technol., 44, 71-75.

[48] Bekri, K., Saint-Louis, R. and Pelletier, E. (2006) Determination of Tributyltin and 4-Hydroxybutyldibutyltin Chlorides in Seawater by Liquid Chromatography with Atmospheric Pressure Chemical Ionization-Mass Spectrometry. Anal. Chim. Acta, 578, 203-212. https://doi.org/10.1016/j.chroma.2015.01.077

[49] Wang, J.C., Zhang, H.J. and Chen, J.P. (2013) Simultaneous Determination of Benzotriazoles and Benzothiazoles in Surface Water by Solid Phase Extraction and High Performance Liquid Chromatography-Tandem Mass Spectrometry. J. Instrum. Anal., 32, 1056-1061. 
Submit or recommend next manuscript to SCIRP and we will provide best service for you:

Accepting pre-submission inquiries through Email, Facebook, LinkedIn, Twitter, etc. A wide selection of journals (inclusive of 9 subjects, more than 200 journals)

Providing 24-hour high-quality service

User-friendly online submission system

Fair and swift peer-review system

Efficient typesetting and proofreading procedure

Display of the result of downloads and visits, as well as the number of cited articles Maximum dissemination of your research work

Submit your manuscript at: http://papersubmission.scirp.org/

Or contact wjet@scirp.org 